\title{
Bone restoration after revision hip arthroplasty with femoral bone defects using extensively porous-coated stems with cortical strut allografts
}

\author{
Zichuan Ding ${ }^{\dagger}$, Tingxian Ling ${ }^{\dagger}$, Ping Mou, Duan Wang, Kai Zhou and Zongke Zhou (D)
}

\begin{abstract}
Background: Stress shielding and bone loss of the femur are of great concern after revision total hip arthroplasty (THA) with extensively porous-coated stems, especially in a femur with already bone loss. The femoral bone remodeling patterns after revision THA with femoral bone defects using extensively porous-coated stems with cortical strut allografts remain unclear.

Methods: We retrospectively reviewed 47 patients who underwent revision THA using extensively porous-coated stems combined with cortical strut allografts and 75 patients without allografts. The minimum follow-up was 2 years. Femoral bone remodeling signs, including stress shielding, bone restoration in bone defect area, distal cortical hypertrophy, and femoral width, were compared between patients with and without cortical strut allografts. Clinical outcomes were also compared between two groups.

Results: Patients with cortical strut allografts showed less severe stress shielding $(P=0.01)$ than patients without allografts. Patients with allografts had more osseous restoration in bone defect area than patients without allografts (63.8\% vs $30.7 \%, P<0.001)$. Femoral width was significantly higher in femur with allografts than in femur without allografts at the immediate postoperative stage and latest follow-up (both $P<0.001$ ). The hip function score, rerevision rate, and complications were comparable between two groups.

Conclusion: The application of cortical strut allografts can decrease the severity of stress shielding, augment osseous restoration in bone defect area and improve femoral bone stock after revision THA using extensively porous-coated stems.
\end{abstract}

Keywords: Revision THA, Bone remodeling, Femoral bone defects, Extensively porous-coated stems, Cortical strut allografts

\footnotetext{
* Correspondence: zongke2017@163.com

${ }^{\dagger}$ Zichuan Ding and Tingxian Ling contributed equally to this work.

Department of Orthopedics, West China Hospital/West China School of

Medicine, Sichuan University, 37\# Wuhou Guoxue Road, Chengdu, People's

Republic of China
}

C The Author(s). 2020 Open Access This article is licensed under a Creative Commons Attribution 4.0 International License, which permits use, sharing, adaptation, distribution and reproduction in any medium or format, as long as you give appropriate credit to the original author(s) and the source, provide a link to the Creative Commons licence, and indicate if changes were made. The images or other third party material in this article are included in the article's Creative Commons licence, unless indicated otherwise in a credit line to the material. If material is not included in the article's Creative Commons licence and your intended use is not permitted by statutory regulation or exceeds the permitted use, you will need to obtain permission directly from the copyright holder. To view a copy of this licence, visit http://creativecommons.org/licenses/by/4.0/. The Creative Commons Public Domain Dedication waiver (http://creativecommons.org/publicdomain/zero/1.0/) applies to the data made available in this article, unless otherwise stated in a credit line to the data. 


\section{Introduction}

Aseptic loosening, infection, osteolysis, periprosthetic fracture, stress shielding, and implant removal can result in femoral bone defects that must be addressed at time of revision total hip arthroplasty (THA). Extensively porous-coated stems have been the predominant choice for revision THA with femoral bone defects. They can bypass the proximal bone defect region and achieve scratch fit fixation in the diaphysis and have shown reliable clinical outcomes in revision THA with bone loss [1-5]. However, stress shielding and further bone loss of the femur are of great concern after revision THA with extensively porous-coated stems, especially in femur with already extensive bone defects. The reported rates of severe stress shielding after revision THA using extensively porous-coated stems ranged from 6 to $22 \%$ [1-6]. The cementless long extensively porous-coated stem with high stiffness distributes some of the loads to the distal femur, and lack of stress in the proximal metaphyseal region leads to bone loss. As a result, proximal osteopenia of stress shielding and distal cortical hypertrophy of stress transfer was often observed. Besides, whether osseous restoration in bone defect area and improvement in femoral bone stock after revision THA using extensively porous-coated stems can be achieved is uncertain [6, 7]. Poor femoral bone stock after revision THA influences the functional outcomes $[8,9]$, increases the risk of aseptic loosening [10], increases the risk of periprosthetic femoral fracture (PFF) [11], and presents particular problems if further revision is required [12]. Improvement in femoral bone stock after revision surgery is of vital importance to eliminate the correlation between severe bone defects and poor clinical outcomes [13].

Cortical strut allografts can successfully reconstruct the bone stock in revision THA. Satisfactory clinical outcomes of revision THA using extensively porous-coated stems combined with cortical strut allografts have been reported [14-17]. It has been demonstrated that incorporated cortical strut allografts can undergo revascularization, be replaced with host bone, regain considerable strength, and undergo adaptive bone remodeling [13, 18-21]. Lack of stress loading on the cortical strut allografts can lead to bone loss of allografts, suggesting cortical strut allografts can also develop stress shielding [15, 22, 23]. However, whether additional application of cortical strut allografts can decrease the severity of stress shielding and promote bone restoration when compared to using extensively porous-coated stems alone remains unclear.

The purpose of this study was to investigate the femoral bone remodeling patterns, including stress shielding, bone restoration in bone defect area, distal cortical hypertrophy, and femoral width, after using extensively porous-coated stems with cortical strut allografts by comparing with those using extensively porous-coated stems alone. Clinical outcomes were also investigated in patients with and without cortical strut allografts.

\section{Patients and methods}

We retrospectively reviewed 144 patients who underwent revision THA at our institution from January 2010 to July 2017. A total of 15 patients were lost to followup after surgery, and five patients had died, with no deaths related to the revision THA. Two patients were reached by telephone at last follow-up and were all satisfied with their hip function but refused to return for follow-up. The remaining 122 patients with a minimum 2-year follow-up were enrolled in this study. All patients were diagnosed with Paprosky type II, III, and IV femoral bone defects. Extensively porous-coated stems combined with cortical strut allografts were applied in 47 patients (allografts group), and stems alone in 75 patients (no allografts group). No significant difference in demographic data was observed between two groups (Table 1). The institutional review board of our hospital approved this retrospective study. All patients provided informed consent for participation.

All femoral components were revised with cementless extensively porous-coated solution stems (DePuy, Warsaw Indiana). When traditional methods fail in attempting to extract a well-fixed stem, extended trochanteric osteotomy (ETO) was performed. When the initial axial and rotational stability of the stems could not be achieved, or the area of cortical bone defects was large, or the thin cortical bone presented a high risk of intraoperative fracture, cortical strut allografts were used. One to three cortical strut allografts were used in different sides of the femur, usually the lateral, medial, or anterior femur, which can be observed in Gruen zone 1-11. The allografts used in these operations were made from tibial bone and previously stored at $80^{\circ} \mathrm{C}$ for at least 3 months in the bone bank of our institution. The allografts were soaked in povidone-iodine solution repeatedly and finally coated with dry-powdered gentamicin and vancomycin, which was all performed on another surgical table under sterile condition. Except use of cortical strut allografts, other techniques and therapy protocol were the same in both groups [24]. Generally, patients were mobilized with partial weight-bearing 1 to 4 weeks after the operation, depending on the degree of preoperative bone defects. Full weight-bearing and ambulation without crutches were allowed after 4 to 12 weeks. Patients were followed up clinically and radiographically after surgery at regular intervals of $1,2,3,6$, and 12 months as well as annually thereafter.

Anteroposterior and lateral radiographs of the femurs at each follow-up time point along with preoperative radiographs were taken and reviewed. Areas around the femoral stem were divided into 14 zones as described by Gruen et al. [25]. The area of stress shielding was 
Table 1 Demographic data

\begin{tabular}{|c|c|c|c|}
\hline Parameters & Allografts group $(n=47)$ & No allografts group $(n=75)$ & $P$ value \\
\hline Male & $29(61.7 \%)$ & $44(58.7 \%)$ & 0.739 \\
\hline Age & $57.2 \pm 16.5(29-83)$ & $53.5 \pm 17.4(33-87)$ & 0.196 \\
\hline Follow-up & $6.4 \pm 2.5(2.3-11.5)$ & $6.0 \pm 2.2(2.2-11.8)$ & 0.302 \\
\hline Primary diagnosis & & & 0.958 \\
\hline Osteonecrosis of the femoral head & $25(53.2 \%)$ & $39(52.0 \%)$ & \\
\hline Developmental dysplasia of the hip & $12(25.5 \%)$ & $16(21.3 \%)$ & \\
\hline Primary osteoarthritis & $6(12.8 \%)$ & $11(14.7 \%)$ & \\
\hline Femoral neck fractures & $3(6.4 \%)$ & $7(9.3 \%)$ & \\
\hline Rheumatoid arthritis & $1(2.1 \%)$ & $2(2.7 \%)$ & \\
\hline Mean time from primary to revision THA & $9.3 \pm 4.2(1-18)$ & $8.9 \pm 4.9(0-17)$ & 0.824 \\
\hline Reason for revision & & & 0.575 \\
\hline $\mathrm{AL}$ & $14(29.8 \%)$ & $29(38.7 \%)$ & \\
\hline PJ & $16(34.0 \%)$ & $24(32.0 \%)$ & \\
\hline PFF & $17(36.2 \%)$ & $22(29.3 \%)$ & \\
\hline Fixation of previous femoral stems & & & 0.739 \\
\hline Cement & $29(61.7 \%)$ & $44(58.7 \%)$ & \\
\hline Cementless & 18 (38.3\%) & 31 (41.3\%) & \\
\hline $\begin{array}{l}\text { Degree of femoral bone defects } \\
\text { (Paprosky classification) }\end{array}$ & & & 0.106 \\
\hline Type II & 9 (19.1\%) & 20 (26.7\%) & \\
\hline Type IIIA & $21(44.7 \%)$ & 36 (48.0\%) & \\
\hline Type IIIB & 12 (25.5\%) & 19 (25.3\%) & \\
\hline Type IV & $5(10.6 \%)$ & $0(0 \%)$ & \\
\hline ETO utilized & $10(21.3 \%)$ & $14(18.7 \%)$ & 0.724 \\
\hline
\end{tabular}

Categorical variables are presented as numbers (percentage). Continuous variables are presented as the means \pm standard deviations (range). $A L$ aseptic loosening, PJl periprosthetic joint infection, PFF periprosthetic femoral fracture, ETO extended trochanteric osteotomy

assessed according to the criteria of Engh and Bobyn [26] and partially modified by Kusano et al. [8]. A small area of stress shielding was defined as bone loss in only Gruen zones $1,7,8$, or 14; a moderate area of stress shielding as any bone loss in Gruen zones 2, 6, 9, or 13; and a large area of stress shielding as bone loss in the remaining Gruen zones: 3, 4, 5, 10, 11, or 12. In addition, we assessed the severity of stress shielding based on bone density according to Moreland and Moreno [27]. Mild stress shielding was indicated when little change in cortical density and thickness was observed. Moderate stress shielding was indicated by significant and obvious loss of cortical density and thickness, and severe stress shielding was indicated by a major, striking, and impressive degree of bone loss. When the cortex of the host bone was covered by allografts, stress shielding was evaluated by comparing earliest radiographs showing that cortical strut allografts were united to the host bone with latest radiographs. Bone restoration in bone defect area was classified as osseous restoration, constant defects, or increasing defects, according to the criteria of Bohm and Bischel [28]. Distal cortical hypertrophy was assessed as previously described by Ritter and Fechtman [29]. Femoral width was measured at the zone with the most severe bone loss, where cortical struts allografts were always applied to augment the bone stock in the allografts group [30].

The fixation and stability of the cementless femoral components were evaluated according to the criteria of Engh et al. [31]. Incorporation of cortical strut allografts to host bone was defined as complete union and bridging between them. Fracture nonunion was defined as a persistent fracture line or absence of bridging callus after six postoperative months [32]. Hip function evaluation was conducted by two observers not involved with the surgical and clinical care of the patients using Harris Hip Score (HHS). Any re-revisions and intraoperative and postoperative complications were recorded.

Two independent observers quantified radiographic parameters to compare the interobserver reliability. Intraobserver reliability was assessed by repeated measurement by the first author on separate occasions, 2 weeks apart. Reliability analysis showed high interobserver and intraobserver agreements for all radiographic parameters, with intraclass 
correlation coefficient (ICC) over 0.75 . Student's $t$ test was utilized to analyze continuous variables. Mann-Whitney $U$ tests and Pearson chi-square tests were performed to analyze ordinal and unordered categorical variables, respectively. The correlation between two ordinal categorical variables was analyzed by Spearman's rank correlation coefficient test. The level of significance was defined as $P<$ 0.05 . Statistical analysis was performed with SPSS v22.0 (IBM, Armonk, NY).

\section{Results}

Patients with cortical strut allografts showed less severe stress shielding than patients without allografts
$(P=0.01)$ (Table 2, Figs. 1,2 , and 3$)$. The area of stress shielding was smaller in the allografts group than in the no allografts group, but it did not reach statistical significance $(P=0.599)$. The severity of stress shielding was positively correlated with preoperative Paprosky classification of femoral bone defects (Spearman's rank correlation coefficient $=0.796, P<0.001$ ), while the area of stress shielding was not associated with preoperative bone defects (Spearman's rank correlation coefficient $=0.14, P=0.326$ ). No difference was observed in HHS among different severities of stress shielding (analysis of variance [ANOVA], $P=0.424$ ) and different areas of stress shielding (ANOVA, $P=0.328$ ).

Table 2 Outcome parameters

\begin{tabular}{|c|c|c|c|}
\hline Parameters & Allografts group $(n=47)$ & No allografts group $(n=75)$ & $P$ value \\
\hline Area of stress shielding & & & 0.599 \\
\hline Small & $28(59.5 \%)$ & $41(54.7 \%)$ & \\
\hline Moderate & $13(27.7 \%)$ & $23(30.7 \%)$ & \\
\hline Large & $6(12.8 \%)$ & $11(14.7 \%)$ & \\
\hline Severity of stress shielding & & & 0.01 \\
\hline Mild & $40(85.1 \%)$ & $48(64.0 \%)$ & \\
\hline Moderate & $5(10.6 \%)$ & $16(21.3 \%)$ & \\
\hline Severe & $2(4.3 \%)$ & $11(14.7 \%)$ & \\
\hline Distal cortical hypertrophy & $14(29.8 \%)$ & $29(38.7 \%)$ & 0.318 \\
\hline Bone restoration in the defect area & & & $<0.001$ \\
\hline Osseous restoration & $30(63.8 \%)$ & $23(30.7 \%)$ & \\
\hline Constant defects & $12(25.5 \%)$ & $30(40.0 \%)$ & \\
\hline Increasing defects & $5(10.6 \%)$ & $22(29.3 \%)$ & \\
\hline \multicolumn{4}{|l|}{ Femoral width $(\mathrm{mm})^{*}$} \\
\hline Pre-operation & $31.7 \pm 4.4(22.6-38.0)$ & $32.2 \pm 5.1(23.9-39.4)$ & 0.457 \\
\hline Immediate post-operation & $42.1 \pm 6.5(29.9-55.6)$ & $32.3 \pm 5.0(23.8-39.4)$ & $<0.001$ \\
\hline Latest follow-up & $38.6 \pm 7.2(25.3-57.7)$ & $31.2 \pm 6.5(22.3-42.5)$ & $<0.001$ \\
\hline Fixation and stability of the stems & & & 0.672 \\
\hline Stable bone ingrowth & $40(85.1 \%)$ & $59(78.7 \%)$ & \\
\hline Stable fibrous ingrowth & $6(12.8 \%)$ & $14(18.7 \%)$ & \\
\hline Unstable & $1(2.1 \%)$ & $2(2.7 \%)$ & \\
\hline Re-revision & $2(4.3 \%)$ & $3(4.0 \%)$ & 0.945 \\
\hline PJI & $0(0 \%)$ & $1(1.3 \%)$ & \\
\hline $\mathrm{AL}$ & $1(2.1 \%)$ & $2(2.7 \%)$ & \\
\hline PFF & $1(2.1 \%)$ & $0(0 \%)$ & \\
\hline \multicolumn{4}{|l|}{$\mathrm{HHS}$} \\
\hline Preoperative points & $41.2 \pm 10.7$ & $43.7 \pm 9.9$ & 0.281 \\
\hline Postoperative points & $84.6 \pm 6.0$ & $84.8 \pm 6.6$ & 0.495 \\
\hline Complications & $4(8.5 \%)$ & $5(6.7 \%)$ & 0.705 \\
\hline Intraoperative fracture & $2(4.3 \%)$ & $3(4.0 \%)$ & \\
\hline Wound infection & $1(2.1 \%)$ & $0(0 \%)$ & \\
\hline Postoperative dislocation & $1(2.1 \%)$ & $2(2.7 \%)$ & \\
\hline
\end{tabular}

*P value was analyzed by the paired $t$ test 


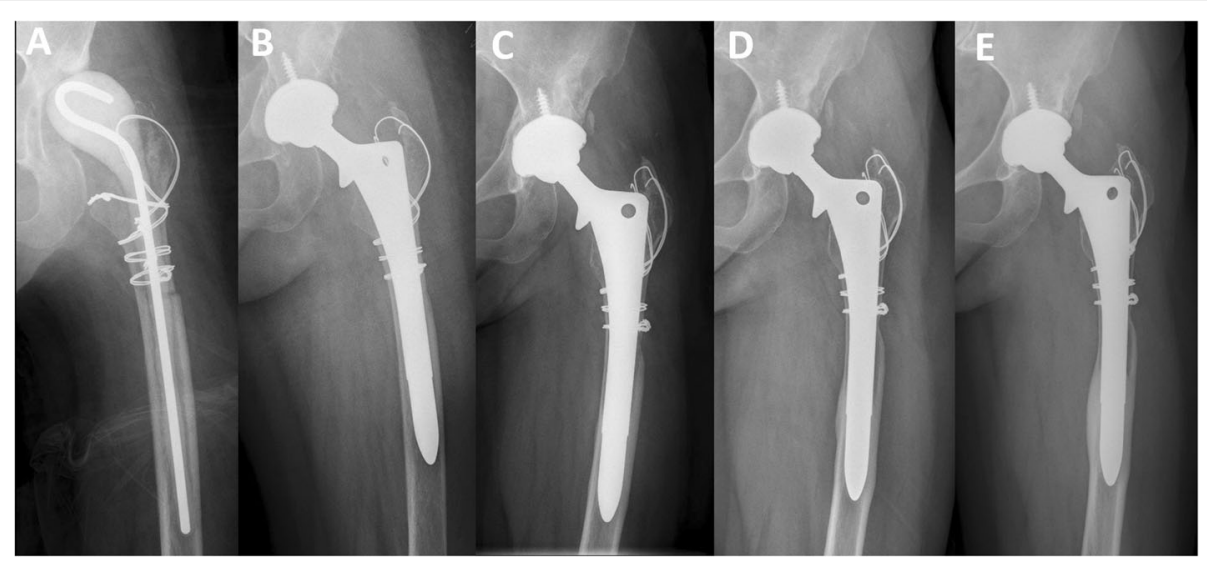

Fig. 1 Anteroposterior radiographs of a 48-year-old woman who underwent revision THA for periprosthetic joint infection. a Radiograph prior to stage 2 revision THA showing the antibiotic-loaded spacer in situ. b Radiograph immediately after revision THA using a cementless extensively porous-coated stem without cortical strut allografts. c Postoperative radiograph at 1 year showing loss of cortical density and thickness in the proximal femur, suggesting moderate area and severity of stress shielding. $\mathbf{d}$ Postoperative radiograph at 5 years showing severe stress shielding and distal cortical hypertrophy on both the medial and lateral sides. e Postoperative radiograph at 10 years showing more severe bone loss and distal cortical hypertrophy

Patients with cortical strut allografts had more osseous restoration in bone defect area than patients without allografts $(63.8 \%$ vs $30.7 \%, P<0.001)$ (Table 2, Figs. 2 and $3)$. Osseous restoration was positively associated with ETO (Pearson chi-square test, $P=0.014$ ). The occurrence of distal cortical hypertrophy showed no difference between the allografts group and no allografts group (29.8\% and 38.7\%, respectively) (Fig. 1). Femoral width was significantly higher in femurs with allografts than in femurs without allografts at the immediate postoperative stage and latest follow-up (both $P<0.001$ ). Compared to the preoperative width, the femoral width at the latest follow-up increased by a mean of $6.9 \mathrm{~mm}(21.8 \%$ of preoperative width) in the allografts group, while the femoral width decreased by $1.1 \mathrm{~mm}$ in the no allografts group at the latest follow-up.

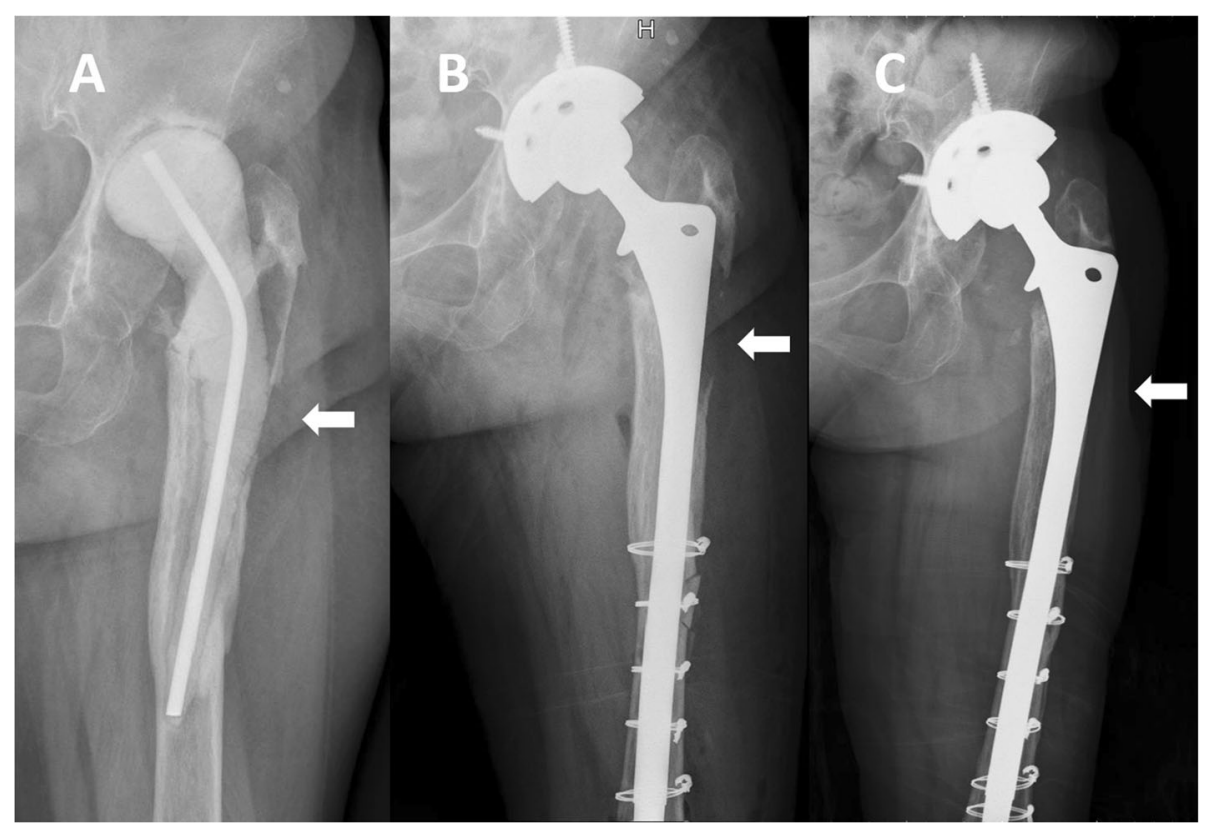

Fig. 2 Anteroposterior radiographs of a 76-year-old man who underwent revision THA for a periprosthetic joint infection using extensively porous-coated stem alone. a Radiograph prior to stage 2 revision THA showing a Paprosky type IIIB femoral bone defect. b Postoperative radiograph at 6 months showing no bone restoration in the bone defect area (white arrow). c Postoperative radiograph at 5 years showing bone defects still existing and moderate stress shielding on both the medial and lateral sides 


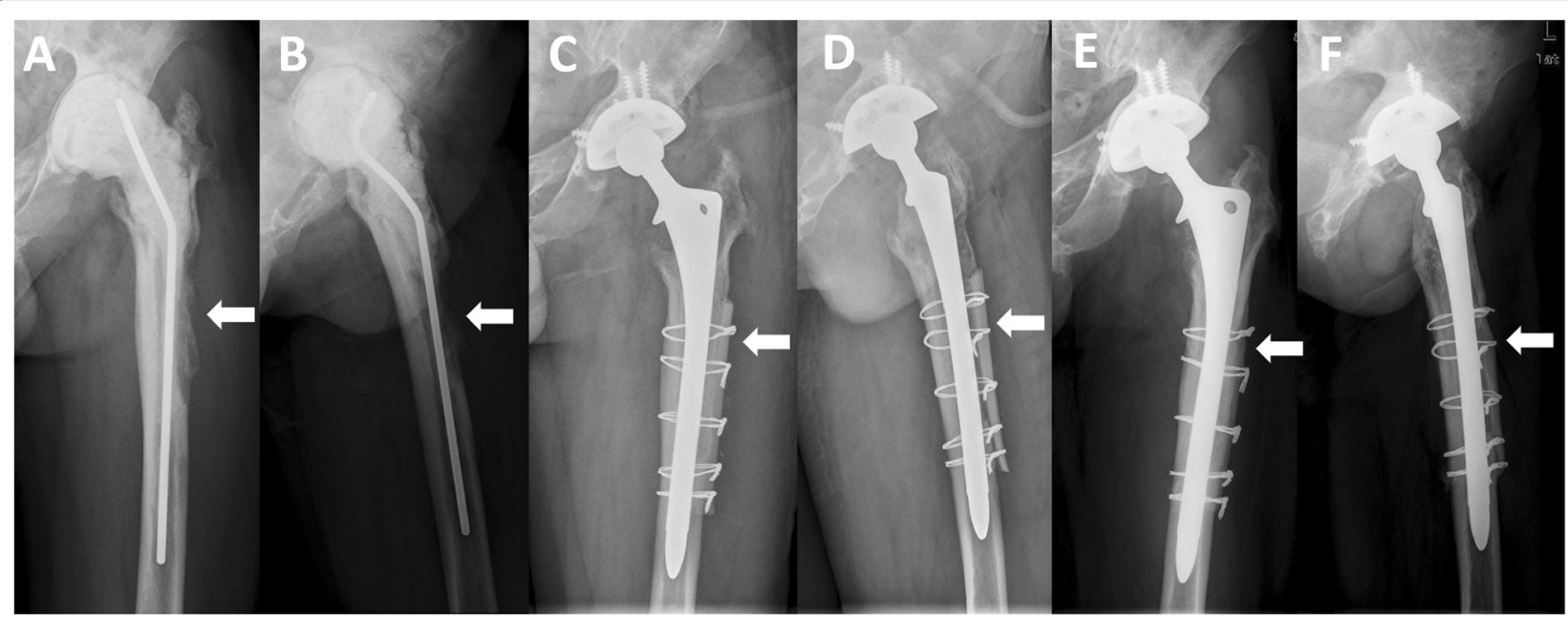

Fig. 3 Radiographs of a 44-year-old man who underwent revision THA for periprosthetic joint infection. a, b Anteroposterior and lateral radiographs prior to stage 2 revision THA showing a Paprosky type IIIA femoral bone defect. $\mathbf{c}$, $\mathbf{d}$ Radiographs immediately after revision THA using an extensively porous-coated stem with cortical strut allografts, showing that the cortical strut allografts bridged the bone defects (white arrow) and supported the thinning cortex. e, $\mathbf{f}$ Postoperative radiographs at 9 years showing successful incorporation of the cortical strut allografts to the host bone, bone restoration in the bone defect area (white arrow), and a significant increase in femoral width. No sign of stress shielding and distal cortical hypertrophy was observed. The stem was assessed as bone ingrowth stable

No difference was observed concerning signs of instability in both groups (Table 2). Incorporation of cortical strut allografts to host bone was confirmed in all 47 patients at a mean follow-up of 9.1 months. All PFFs and ETOs achieved union. The re-revision rates were comparable between the allografts and no allografts groups $(4.3 \%$ vs $4.0 \%, P=0.945)$. One PFF occurred in the allografts group and one acute hematogenous periprosthetic joint infection occurred in the no allografts group, but both stems were evaluated as stable in rerevision surgery. The HHS showed significant improvement after revision THA in both groups (both $P<0.001$ ). No significant difference was found in intraoperative and postoperative complications between two groups.

\section{Discussion}

Stress shielding and further bone loss of the femur with already deficient bone stock are of great concern after revision THA using extensively porous-coated stems [1-5]. Enhancement of femoral bone stock after revision THA can improve functional outcomes, decrease the risk of PFF and aseptic loosening, and render further re-revision easier [8-13]. Cortical strut allografts were reported to successfully reconstruct the femur and improve bone stock in revision THA with bone defects [14-16]. However, whether additional application of cortical strut allografts can decrease the severity of stress shielding and promote bone restoration when compared to using extensively porous-coated stems alone remains unclear. To the best of our knowledge, no previous studies have compared the femoral bone remodeling patterns after revision THA using extensively porous-coated stems with and without cortical strut allografts.

Although we found that extensively porous-coated stems with and without cortical strut allografts can both provide satisfactory clinical outcomes after revision THA with bone defects, the most striking finding in our study was that additional application of cortical strut allografts can further decrease the severity of stress shielding, augment osseous restoration in bone defect area, and reconstruct femoral bone stock. Although we did not find any difference in functional outcomes among patients with different degrees of stress shielding, we speculated that severe bone loss may result in worse hip function at longer follow-up time, as previously described $[8,9]$. Decreasing the severity of stress shielding and improving bone stock can eliminate the correlation between severe bone defects and poor clinical outcomes [13]. Besides, we believe that the promotion of bone restoration after application of allografts can provide superior longevity of revision stem and decrease the risk of aseptic loosening and periprosthetic fracture at longer follow-up time [10-12]. Moreover, application of allografts can provide a better bone stock situation when a further revision is required. Since we found the severity of stress shielding was positively correlated with degree of preoperative bone defects, which is in accordance with previous findings $[1,2,33]$, we suggest, in revision THA cases with severe femoral bone defects, use of cortical strut allografts is a reliable way to reduce bone loss, promote bone restoration and improve femoral bone stock. 
Many previous studies have assessed the severity of stress shielding around extensively porous-coated stems based on the area of stress shielding. The reported rates of severe stress shielding, defined as a large area of bone loss extending to the femoral diaphysis, ranged from 6 to $22 \%$ [1-6]. In this study, stress shielding extending to the femoral diaphysis was observed in $12.8 \%$ and $14.7 \%$ of patients in the allografts group and no allografts group, respectively. However, it did not reach statistical significance. We also investigated the severity of stress shielding based on the intensity of bone loss and found patients with cortical strut allografts had a significantly lower rate of severe stress shielding than patients without allografts $(4.3 \%$ vs $14.7 \% ; P=0.01)$. In summary, the application of allografts decreased the severity of stress shielding and delayed the process of stress shielding, although stress shielding still developed at the united allografts and host bone.

The decreased severity and delayed process of stress shielding after application of cortical strut allografts may be explained as follows. First, the high rate of incorporation of cortical strut allografts leads to significant increase of bone mass, which can limit the influence of stress shielding on bone stock. Second, it has been demonstrated that after union occurs, cortical strut allografts can be invaded by osteoclasts, osteoblasts, and vascular and be replaced with host bone and maintain biologically active, thus further responding to stress and undergoing adaptive bone remodeling $[13,18]$ Cortical strut allografts change the biological environment of host bone and coordinate the host bone to respond to stress. Third, the stress transfer in stem and host bone depends on the stiffness of the stem and host bone [34]. Use of cortical strut allografts leads to an increase in the stiffness of host bone and consequently enhances the stress transfer in host bone $[35,36]$. The cortical strut allografts have considerable strength and similar modulus of elasticity as host bone, thus minimizing modulus mismatch and decrease stress shielding in the host bone [20,37].

Although bone restoration in bone defect area is expected after revision using cementless stems alone, Richards et al. [7] and Kimura et al. [38] reported that the osseous restoration in bone defect area only occurred in $8.1 \%$ and $50.0 \%$ of the patients, respectively. This study has shown $63.8 \%$ of the femurs in the allografts group and $30.7 \%$ of the femurs in the no allografts group had osseous restoration. Successful incorporation of allografts to host bone leads to augmentation of osseous restoration by a large margin. Osseous restoration was positively associated with ETO, which can be explained by the fracture healing process caused by ETO, including cytokine secretion and vascular invasion [32, 33]. In the allografts group, we found a significant enhancement of femoral width, which reflected the reconstruction of the femoral bone stock through the application of cortical strut allografts. When comparing the immediate postoperative and latest follow-up femoral widths to the preoperative femoral width, an increase of $10.4 \mathrm{~mm}$ and $6.9 \mathrm{~mm}$, respectively, was observed. This result was in agreement with the previously reported data [30, 39]. A slight decrease in the femoral width $(3.5 \mathrm{~mm})$ was observed after 6-year followup, which was consistent with the stress shielding developed in allografts and host bone. In contrast to patients in the allografts group, patients in the no allografts group showed decreased femoral width over time.

Distal cortical hypertrophy, seen with new cortical bone formation and increase in distal cortical thickness, suggests a transfer of the majority of the load from the distal part of stem to the femur [29]. The distal cortical hypertrophy occurred less in the allografts group than in the no allografts group in our study ( $29.8 \%$ vs $38.7 \%)$, suggesting that use of cortical strut allografts led to an enhancement of loading transfer in proximal host bone and consequently decreased the load transferred from the distal part of stem to the femur. However, it did not reach statistical significance $(P=0.318)$. Distal cortical hypertrophy and stress shielding are similar phenomena which are caused by the modified femoral loading patterns after revision THA using extensively porous-coated stems. Cortical strut allografts seem to be a reliable approach to change the mechanical and biological environment of host bone and improve the bone remodeling patterns.

The present study has several limitations. First, a mean follow-up time of 6.1 years was relatively short. It might be inadequate to determine the influence of radiographic changes on clinical outcomes and distinguish the difference between two groups. Second, the minimum followup time was only 2 years. However, we found the bone remodeling progressed little with time over 2 years, which was in accordance with previously reported by Engh and Bobyn [26]. Third, the bone remodeling patterns were assessed on plain radiographs in our study. Dual-energy X-ray absorptiometry or computed tomography can detect and quantify bone density changes with high precision and reproducibility. Further studies with longer follow-up and more precise detection methods are required to investigate the femoral bone remodeling patterns after using cortical strut allografts.

\section{Conclusion}

In conclusion, the application of cortical strut allografts can decrease the severity of stress shielding, augment osseous restoration in bone defect area, and improve femoral bone stock after revision THA using extensively porous-coated stems. We suggest, in revision THA cases with severe femoral bone defects, use of cortical strut allografts is a reliable way to reduce bone loss, promote bone restoration, and improve femoral bone stock. 


\section{Abbreviation}

THA: Total hip arthroplasty; ETO: Extended trochanteric osteotomy; PFF: Periprosthetic femoral fracture; HHS: Harris Hip Score; ICC: Intraclass correlation coefficient; ANOVA: Analysis of variance

\section{Acknowledgements}

Not applicable

\section{Authors' contributions}

ZC-D and TX-L performed data collection and analysis. P-M, D-W, and K-Z performed manuscript writing. ZK-Z drafted the work. The authors read and approved the final manuscript.

\section{Funding}

Not applicable

\section{Availability of data and materials}

The datasets analyzed during the current study are available from the corresponding author on reasonable request.

\section{Ethics approval and consent to participate}

This retrospective study was approved by the Institutional Review Board of West China Hospital, Sichuan University (ID number 2012-268). All patients provided informed consent for participation.

\section{Consent for publication}

Not applicable

\section{Competing interests}

The authors declare that they have no competing interests

Received: 3 March 2020 Accepted: 20 May 2020

Published online: 27 May 2020

\section{References}

1. Paprosky WG, Greidanus NV, Antoniou J. Minimum 10-year-results of extensively porous-coated stems in revision hip arthroplasty. Clin Orthop Relat Res. 1999;369:230-42

2. Moreland JR, Bernstein ML. Femoral revision hip arthroplasty with uncemented, porous-coated stems. Clin Orthop Relat Res. 1995;319:141-50.

3. Nadaud MC, Griffin WL, Fehring TK, Mason JB, Tabor OB Jr, Odum S, et al. Cementless revision total hip arthroplasty without allograft in severe proximal femoral defects. J Arthroplast. 2005;20(6):738-44.

4. Thomsen PB, Jensen NJ, Kampmann J, Baek HT. Revision hip arthroplasty with an extensively porous-coated stem - excellent long-term results also in severe femoral bone stock loss. Hip Int. 2013;23(4):352-8.

5. Chung LH, Wu PK, Chen CF, Chen WM, Chen TH, Liu CL. Extensively porouscoated stems for femoral revision: reliable choice for stem revision in Paprosky femoral type III defects. Orthopedics. 2012;35(7):e1017-21.

6. Fukui K, Kaneuji A, Sugimori T, Ichiseki T, Matsumoto T. Bone remodeling after a mean of 10 years in diaphyseal cortical defects repaired with femoral revision using bypass fixation of extensively porous-coated stems with high stiffness. Eur J Orthop Surg Traumatol. 2015;25(4):741-7.

7. Richards CJ, Duncan CP, Masri BA, Garbuz DS. Femoral revision hip arthroplasty: a comparison of two stem designs. Clin Orthop Relat Res. 2010; 468(2):491-6.

8. Kusano T, Seki T, Higuchi Y, Takegami Y, Osawa Y, Ishiguro N. Preoperative canal bone ratio is related to high-degree stress shielding: a minimum $5 y$ Year follow-up study of a proximally hydroxyapatite-coated straight tapered titanium femoral component. J Arthroplast. 2018;33(6):1764-9.

9. Goosen JH, Swieringa AJ, Keet JG, Verheyen CC. Excellent results from proximally HA-coated femoral stems with a minimum of 6 years follow-up: a prospective evaluation of 100 patients. Acta Orthop. 2005;76(2):190-7.

10. Wilkinson JM, Hamer AJ, Rogers A, Stockley I, Eastell R. Bone mineral density and biochemical markers of bone turnover in aseptic loosening after total hip arthroplasty. J Orthop Res. 2003;21(4):691-6.

11. Lindahl $\mathrm{H}$. Epidemiology of periprosthetic femur fracture around a total hip arthroplasty. Injury. 2007;38(6):651-4.

12. Callaghan JJ, Salvati EA, Pellicci PM, Wilson PD Jr, Ranawat CS. Results of revision for mechanical failure after cemented total hip replacement, 1979 to 1982. A two to five-year follow-up. J Bone Joint Surg Am. 1985;67(7): 1074-85.

13. Emerson RH Jr, Malinin Tl, Cuellar AD, Head WC, Peters PC. Cortical strut allografts in the reconstruction of the femur in revision total hip arthroplasty. A basic science and clinical study. Clin Orthop Relat Res. 1992; 285:35-44.

14. Mokka J, Keemu H, Koivisto M, Stormi T, Vahlberg T, Virolainen P, et al. Experience of structural onlay allografts for the treatment of bone deficiency in revision total hip arthroplasty. Scand J Surg. 2013;102(4):265-70.

15. Pak JH, Paprosky WG, Jablonsky WS, Lawrence JM. Femoral strut allografts in cementless revision total hip arthroplasty. Clin Orthop Relat Res. 1993;295: $172-8$.

16. Kim YH, Park JW, Kim JS, Rastogi D. High survivorship with cementless stems and cortical strut allografts for large femoral bone defects in revision THA. Clin Orthop Relat Res. 2015;473(9):2990-3000.

17. Ding ZC, Ling TX, Yuan MC, Qin YZ, Mou P, Wang HY, et al. Minimum 8-year follow-up of revision THA with severe femoral bone defects using extensively porous-coated stems and cortical strut allografts. BMC Musculoskelet Disord. 2020;21(1):218

18. Head WC, Wagner RA, Emerson RH Jr, Malinin TI. Restoration of femoral bone stock in revision total hip arthroplasty. Orthop Clin North Am. 1993: 24(4):697-703.

19. Head WC, Malinin TI. Results of onlay allografts. Clin Orthop Relat Res. 2000; 371:108-12.

20. Malinin T, Latta LL, Wagner JL, Brown MD. Healing of fractures with freezedried cortical bone plates. Comparison with compression plating. Clin Orthop Relat Res. 1984;190:281-6.

21. Wu LD, Xiong Y, Yu HC. Effects of rhBMP-2 on cortical strut allograft healing to the femur in revision total hip arthroplasties: an experimental study. Int Orthop. 2007:31(5):605-11.

22. Barden B, Fitzek JG, Huttegger C, Loer F. Supportive strut grafts for diaphyseal bone defects in revision hip arthroplasty. Clin Orthop Relat Res. 2001;387:148-55.

23. Buoncristiani AM, Dorr LD, Johnson C, Wan Z. Cementless revision of total hip arthroplasty using the anatomic porous replacement revision prosthesis. J Arthroplast. 1997;12(4):403-15.

24. Ding ZC, Xu B, Liang ZM, Wang HY, Luo ZY, Zhou ZK. Limited influence of comorbidities on length of stay after total hip arthroplasty: experience of enhanced recovery after surgery. Orthop Surg. 2020;12(1):153-61.

25. Gruen TA, McNeice GM, Amstutz HC. "Modes of failure" of cemented stemtype femoral components: a radiographic analysis of loosening. Clin Orthop Relat Res. 1979;141:17-27.

26. Engh CA, Bobyn JD. The influence of stem size and extent of porous coating on femoral bone resorption after primary cementless hip arthroplasty. Clin Orthop Relat Res. 1988;231:7-28.

27. Moreland JR, Moreno MA. Cementless femoral revision arthroplasty of the hip: minimum 5 years followup. Clin Orthop Relat Res. 2001;393:194-201.

28. Bohm P, Bischel O. Femoral revision with the Wagner SL revision stem evaluation of one hundred and twenty-nine revisions followed for a mean of 4.8 years. J Bone Joint Surg Am. 2001;83-A(7):1023-31.

29. Ritter MA, Fechtman RW. Distal cortical hypertrophy following total hip arthroplasty. J Arthroplast. 1988;3(2):117-21.

30. Buttaro MA, Costantini J Comba F, Piccaluga F. The use of femoral struts and impacted cancellous bone allograft in patients with severe femoral bone loss who undergo revision total hip replacement: a three- to nineyear follow-up. J Bone Joint Surg (Br). 2012;94(2):167-72.

31. Engh CA, Massin P, Suthers KE. Roentgenographic assessment of the biologic fixation of porous-surfaced femoral components. Clin Orthop Relat Res. 1990;257:107-28.

32. Ding ZC, Lin YK, Gan YK, Tang T. Molecular pathogenesis of fracture nonunion. J Orthop Translat. 2018;14:45-56.

33. Huang $Y$, Shao H, Zhou Y, Gu J, Tang H, Yang D. Femoral bone remodeling in revision total hip arthroplasty with use of modular compared with monoblock tapered fluted titanium stems: the role of stem length and stiffness. J Bone Joint Surg Am. 2019;101(6):531-8.

34. Riviere C, Grappiolo G, Engh CA Jr, Vidalain JP, Chen AF, Boehler N, et al. Long-term bone remodelling around 'legendary' cementless femoral stems. EFORT Open Rev. 2018:3(2):45-57.

35. Sariyilmaz K, Dikici F, Dikmen G, Bozdag E, Sunbuloglu E, Bekler B, et al. The effect of strut allograft and its position on Vancouver type B1 periprosthetic femoral fractures: a biomechanical study. J Arthroplast. 2014;29(7):1485-90. 
36. Zdero R, Walker R, Waddell JP, Schemitsch EH. Biomechanical evaluation of periprosthetic femoral fracture fixation. J Bone Joint Surg Am. 2008: 90(5):1068-77.

37. Sheth NP, Melnic CM, Rozell JC, Paprosky WG. Management of severe femoral bone loss in revision total hip arthroplasty. Orthop Clin North Am. 2015;46(3):329-42 ix.

38. Kimura H, Kaneuji A, Sugimori T, Matsumoto T. Revision total hip arthroplasty by nonmodular short and long cementless stems. J Orthop Sci. 2008;13(4):335-40.

39. Lim CT, Amanatullah DF, Huddleston JI 3rd, Hwang KL, Maloney WJ, Goodman SB. Cortical strut allograft support of modular femoral junctions during revision total hip arthroplasty. J Arthroplast. 2017;32(5):1586-92.

\section{Publisher's Note}

Springer Nature remains neutral with regard to jurisdictional claims in published maps and institutional affiliations.

Ready to submit your research? Choose BMC and benefit from:

- fast, convenient online submission

- thorough peer review by experienced researchers in your field

- rapid publication on acceptance

- support for research data, including large and complex data types

- gold Open Access which fosters wider collaboration and increased citations

- maximum visibility for your research: over $100 \mathrm{M}$ website views per year

At BMC, research is always in progress.

Learn more biomedcentral.com/submissions 